\title{
9
}

\author{
Ramón Casilda Béjar*
}

\section{LOS BANCOS EN EVOLUCIÓN}

Los bancos se encuentran sufriendo una evolución, que nos obliga a preguntarnos si se corresponde con una evolución propia de tendencias generalizadas o, más bien, de una reinvención profunda del negocio, fruto de la crisis financiera de 2008, cuyos impactos han sido de tal calibre y magnitud que, aún hoy, se sienten sus efectos en los desequilibrios macroeconómicos, las finanzas públicas, el sistema bancario, el empresarial y la ciudadanía. La industria bancaria, pilar fundamental de la economía de mercado y en consecuencia del sistema financiero y la economía mundial, debe hacer frente a competidores inéditos que han surgido con una vigorosa fuerza. Nos referimos a las FinTech y, particularmente, a la BigTech, cuya fuerza reside en su tamaño, innovación y potencia tecnológica, sin olvidar que tienen la gran ventaja adicional de no estar sujetas a la estricta y exigente regulación bancaria.

Palabras clave: Banco Central Europeo, BigTech, FinTech, criptomonedas, crisis, consolidación, evolución, GAFA, innovación, modelo de negocio, reinvención, rentabilidad.

Clasificación JEL: G21, O31.

\section{Los bancos en evolución}

Los bancos se encuentran sufriendo una evolución ${ }^{1}$ que nos obliga a preguntarnos si se corresponde con una evolución propia de tendencias generalizadas o, más bien, de una reinvención profunda del negocio, fruto de la crisis financiera de 2008, cuyos impactos han sido de

\footnotetext{
* Consultor Iberoamericano. Profesor del Instituto de Estudios Bursátiles; y del Instituto Universitario de Investigación en Estudios Latinoamericanos de la Universidad de Alcalá.

Versión de octubre de 2019.

DOI: https://doi.org/10.32796/bice.2020.3119.6961

1 También el capitalismo se encuentra, como sistema, sufriendo una profunda «reinvención» como consecuencia de la crisis económica iniciada en agosto de 2007 en EE UU, bautizada como la Gran Recesión. Para más detalle, véase Capitalismo. Crisis y Reinvención (Casilda, 2019).
}

tal calibre y magnitud que, aún hoy, se sienten sus efectos en los desequilibrios macroeconómicos, las finanzas públicas, el sistema bancario, el empresarial y la ciudadanía.

Podemos decir que existe una estrecha relación entre los desequilibrios macroeconómicos, las finanzas públicas, la solidez del sistema bancario, el empresarial y el nivel económico de la ciudadanía. Es por ello que las crisis financieras tienen un impacto en la economía real, principalmente i) por medio del crédito y su falta de disponibilidad, lo que finalmente afecta al consumo, a la inversión y al empleo; ii) por la vía patrimonial de reducción de la demanda y pérdida de valor; iii) por la pérdida de confianza, que implica una contracción de la demanda que puede llegar a reducciones del PIB y $\triangleright$ 
finalmente iv) por las reformas fiscales, que en el caso de la crisis de 2008 han sido de gran calado para contrarrestar el déficit público (Muñoz, 2016).

A partir de la década de 1970, la formación del mercado de los eurodólares, como paso esencial para la desregulación de los mercados financieros, ha tenido una influencia en la economía mundial que no ha dejado de crecer, hasta el punto de que la problemática, las actividades y los desafíos relacionados con las finanzas ocupan una situación predominante en la economía y en la gobernanza global.

Desde entonces, el tamaño de los bancos tampoco ha dejado de crecer. Uno de los mayores inversores son los fondos institucionales, presentes en casi todos los grandes bancos del mundo. En el informe Posición Internacional de la Empresa Cotizada Española $2015^{2}$ se señala que los principales fondos institucionales cuentan en sus carteras con la mayoría de las compañías que forman parte del IBEX 35.

Según FactSet, el valor de las participaciones alcanzaba 113.512 millones de euros a través de 8.673 fondos, representando más del $15 \%$ de la capitalización de las cotizadas. Los inversores institucionales estadounidenses son los principales propietarios de acciones del IBEX 35, por un valor de 36.562 millones de euros a través de 1.293 fondos. El fondo estadounidense Black Rock, el mayor del mundo, con 6 billones de dólares (cinco veces el PIB de España), mantiene en el IBEX 35 una posición importante en Santander, BBVA, Sabadell, Bankinter, CaixaBank, Iberdrola, Enagás, REE, Repsol, Telefónica, ACS, Cellmex e IAG, entre otras. Por su parte, el Fondo Global de Pensiones del Gobierno de Noruega, el mayor

2 Posición Internacional de la Empresa Cotizada Española. Bolsa y Mercados de España. Madrid, 2015. fondo soberano del mundo, administrado por Norges Bank Investment Management ${ }^{3}$, se ha convertido en el segundo accionista del Santander $(2,6 \%)$ y CaixaBank $(3,01 \%$, solo por detrás de Criteria, que controla el $40 \%$ ), Sabadell $(3 \%)$, BBVA $(2,6 \%)$, Liberbank $(2 \%)$ y Bankia (1,8\%).

\section{La evolución de los bancos y la consolidación del sector}

Sobre la evolución de los bancos y la consolidación del sector, el expresidente del Banco Central Europeo (BCE), Mario Draghi, consideraba que el sector está superpoblado: «Parte de la debilidad estructural de los bancos en Europa es imputable a una sobrecapacidad. No en forma de crédito, sino de empleados y sucursales. Hay una necesidad real de consolidación en el sector. Existe una relación entre las economías de escala y la capacidad para llevar a cabo las inversiones necesarias para mejorar la tecnología y ser competitivos ${ }^{4}$. «Los bancos se quejan de los tipos de interés como causa de su falta de rentabilidad, pero hay entidades que tienen una ratio entre los costes y los ingresos de entre el $80 \%$ y el $90 \%$ ». Para Draghi está muy claro que se hace necesario llevar a cabo un proceso de consolidación mediante fusiones transfronterizas, que permitan reducir costes, siendo el problema $\triangleright$

3 Norges Bank Investment Management (NBIM) administra el Fondo Global de Pensiones del Gobierno de Noruega, en representación del Ministerio de Finanzas, propietario del fondo en nombre del pueblo noruego. Es el mayor fondo soberano del mundo, y ha superado por primera vez los 10 billones de coronas de valor de mercado (casi un billón de euros), según ha confirmado Norges Bank Investment Management, entidad adscrita al Banco Central de Noruega. Como referencia, la cifra del fondo se aproxima al PIB total de España, que alcanzó los 1,2 billones de euros en 2018.

4 El sector bancario es el único que cotiza por debajo del valor en libros contables, presionado por el actual entorno de tipos, y trasmite inquietud a largo plazo. A diferencia de Estados Unidos, en Europa cada país tiene su grupo de grandes bancos, y a ellos se dirige la propuesta de Mario Draghi. 
de los bancos una cuestión de economías de escala ${ }^{5}$.

Al respecto, el exgobernador del Banco de España, Luis María Linde, indicaba: «Es evidente que la vía de la consolidación no puede darse por cerrada o agotada, no solo en España, sino en el conjunto del área del Mecanismo Único de Supervisión». Esta opción, referida a fusiones o absorciones entre entidades bancarias españolas o transfronterizas, junto a la menor densidad de oficinas y una mayor innovación tecnológica, era la alternativa propuesta para ajustar la estrategia y aumentar la rentabilidad de los bancos, después del proceso de concentración del sector, que ha pasado de 59 entidades (14 bancos y 45 cajas) a las 18 actuales (16 bancos y 2 cajas) ${ }^{6}$.

El Banco de España y el Banco Central Europeo son proclives a que se inicie el proceso de fusiones, aunque el ejemplo contrario lo han protagonizado la unión fallida de Unicaja y Liberbank. De manera que las señales de los bancos españoles indican que, de no producirse circunstancias favorables que lo propicien, han dado por concluido el proceso de consolidación del sector.

Sabemos que las dos principales razones que pueden motivar un proceso de fusión o absorción, con la complejidad y riesgos que conlleva, son la consecución de un mayor tamaño o la detección de entidades cuya gestión puede ser mejorada. Ello puede sintetizarse en las denominadas sinergias operativas por economías de escala, mediante una mayor eficiencia o en una mayor cuota de mercado,

\footnotetext{
5 Mario Draghi realizó estas declaraciones durante la rueda de prensa con motivo de la reunión del consejo del BCE (10 de abril de 2019). Además señaló que los tipos se dejaron en mínimos históricos $(0 \%)$ $-0,4 \%)$. Confía en «que se mantengan en los niveles actuales al menos hasta el final de 2019». Y no será Mario Draghi quien realice la futura subida, ya que se su mandato finalizó en octubre de 2019.

6 Luis María Linde, discurso de apertura del XI Encuentro del Sector Bancario, IESE. Madrid, 10 de diciembre de 2015.
}

reduciendo el exceso de capacidad y eliminando duplicidades.

Las economías de escala son tratadas por altos profesionales del sector. A ellas se refería el vicepresidente y consejero delegado del Santander, José Antonio Álvarez (2008), cuando propuso un riguroso control de los costes, exponiendo que «es también importante explotar las economías de escala, que se alcanzan a través de un tamaño crítico de mercado».

Sin embargo, la literatura académica concluye que la reducción de costes por economías de escala no suele ser relevante en entidades bancarias de gran tamaño, por lo que podemos estimar que no parecen ser las tan citadas sinergias operativas las que justifican un proceso de fusión. En el ámbito estrictamente nacional, parece que la causa que principalmente motiva ese hipotético proceso de fusiones en nuestras entidades es reducir la capacidad en el sector y, por tanto, la competencia, dando servicio a los clientes con un menor número de sucursales y de entidades.

Desde la perspectiva de la protección del bien común, la mayor concentración puede reducir la asunción de riesgos excesivos para incrementar la rentabilidad. Sin embargo, supone una menor competencia que puede imponer mayores precios o una oferta de menor calidad, aunque ello podría atraer a nuevos competidores en el marco de la unión bancaria. Así mismo, la mayor concentración supone una más difícil supervisión y un incremento del riesgo sistémico o del coste asociado al mismo (Arderiu, 20 de enero de 2016).

Con la consolidación se pueden presentar dos tipos importantes de ventajas en costes: i) las ventajas derivadas de posibles economías de escala de cada unidad de negocio - cuanto mayor sea el volumen de operaciones para un nivel de gasto fijo o de inversiones, $\square$ 
mayor será la eficacia de cada unidad de negocio-; y ii) las ventajas derivadas de compartir costes entre distintas unidades de negocio, de manera que el coste total de ofrecer las actividades mediante unidades separadas sea inferior al coste que produce cuando se ofrecen conjuntamente.

También la literatura académica indica que la reducción de costes por economías de escala no suele ser relevante en entidades bancarias de gran tamaño, por lo que podemos estimar que no parecen ser las tan citadas sinergias operativas por economías de escala las que justifican un proceso de consolidación. La mayoría de los estudios empíricos concluyen que la reducción de costes por economías de escala no suele ser relevante en entidades bancarias de gran tamaño al agotarse en niveles de ingresos pequeños.

Aunque conviene recordar que no siempre ha sido el tamaño lo que ha favorecido la adaptación a los cambios que deben afrontarse, en este caso regulatorios y competitivos. Recordemos que la razón dominante en el sector bancario español para justificar la consolidación durante la segunda mitad de la década de 1980 eran las supuestas economías de escala asociadas a un mayor tamaño. Se afirmaba que los grandes bancos españoles tenían una dimensión insuficiente para competir en el mercado financiero único de 1993, y que el modelo adecuado para hacerlo era por medio de una política de fusiones, según el informe de 1987 del profesor británico Jack Revell, encargado por Pedro Toledo, presidente del Banco de Vizcaya. Revell era el experto con mayor prestigio en temas bancarios en Europa y, sin dudas, ejerció una evidente influencia para determinar el panorama y futuro del sector bancario español en esa época tan convulsa por la que atravesaban bancos y cajas de ahorros en la búsqueda más eficiente de su organización, estrategia y de su modelo de negocio.

Como se ha demostrado, las fusiones no son buenas o malas en sí mismas, sino que más bien dependen en gran parte del éxito de, al menos, dos cuestiones claves: i) el encaje natural de las entidades que se fusionan, tanto desde un punto de vista de mercado externo como desde un punto de vista interno de organización y tecnología; y ii) el encaje de las personas y su mutua receptividad y empatía, así como de la compatibilidad de valores y cultura.

Tenemos, pues, en España, un sector bancario que nos ofrece ricas experiencias sobre los procesos de consolidación. Son procesos que en ocasiones, por su alta complejidad, escapan al plan inicial y producen conflictos entre los sistemas operativos, control y gestión de riesgos, cultura y valores, o por una combinación de todos ellos.

En definitiva, la cuestión es saber a quién beneficia el proceso de consolidación y con qué indicadores van a medirse sus resultados. La incógnita a corto plazo es saber quién puede iniciarlo, lo que no resulta una cuestión menor, atendiendo a lo que del mismo puede derivarse, así como por la presión y la velocidad que pueden adquirir los sucesivos procesos. De cualquier manera, conviene advertir que no siempre ha sido la consolidación lo que ha favorecido la adaptación a los cambios que deben afrontarse, en este caso, regulatorios y tecnológicos.

A la propuesta de fusiones bancarias realizada por el expresidente del BCE, Mario Draghi, la presidenta del Santander, Ana Botín, fue una de las primeras en responderle (abril, 2019): «No pienso fusionarme con otro banco de la zona euro. Para la consolidación del sector a nivel europeo y la creación de entidades $\triangleright$ 
fuertes, rentables, con estructuras más sencillas y procesos más ágiles, es preciso avanzar en la unión bancaria. Todavía tienen que pasar seis o siete cosas antes de que se den las condiciones para hacer ese tipo de fusiones».

Sin embargo, uno de los datos más destacados que refleja el informe Perspectivas España 2019 (KPMG-CEOE, junio 2019) ${ }^{7}$ es que el $87 \%$ de los encuestados espera una nueva ola de fusiones entre bancos españoles, que además tendrá lugar a medio plazo, según la mayoría. El sector bancario español continúa afrontando un panorama complejo derivado del retraso de la normalización monetaria y el mantenimiento de tipos de interés bajos, lo que afecta a su rentabilidad, obligándoles a desarrollar iniciativas de reestructuración y de control de costes ${ }^{8}$.

La incógnita sigue en el aire y nadie sabe quién o quienes podrían comenzarlo. Podrían haberlo hecho los dos más importantes bancos alemanes, Deutsche Bank y Commerzbank, que mantuvieron conversaciones con tal propósito, pero no avanzaron. De haberse fusionado, habría surgido el tercer mayor banco comercial de la zona euro por volumen de activos, con casi 2 billones de euros, unos depósitos de 840.000 millones de euros y una plantilla de 140.000 empleados. Sin embargo, su valor bursátil sumaba 22.700 millones de euros (12.700 millones y 10.000 millones, respectivamente).

Deutsche Bank, la otrora entidad bancaria más importante europea, y la de mayor riesgo sistémico del mundo según el Fondo Monetario Internacional, se encuentra rompiendo récords

\footnotetext{
7 Informe realizado por KPMG en colaboración con la Confederación Española de Organizaciones Empresariales (CEOE). Recoge la opinión de directivos y empresarios españoles sobre la situación económica actual y sus expectativas de negocio a corto y medio plazo de cara a 2019 por la desaceleración mundial y los riesgos geopolíticos.

8 Francisco Uría, socio responsable del sector financiero de KPMG en España y socio principal de KPMG Abogados.
}

negativos. La capitalización bursátil de $12.700^{9}$ millones de euros (quince veces menos que su máximo histórico) es cinco veces menor que la del primer banco español, Santander, que alcanza unos 64.000 millones de euros, casi tres veces más que la del banco resultante de Deutsche Bank y Commerzbank. Y Deutsche también vale menos que BBVA y CaixaBank.

En la Unión Europea, y antes de que se materialice el brexit, solo el británico HSBC, con algo más de 2,5 billones de euros, y el francés BNP Paribas, con más de 2 billones, superarían en tamaño a la suma de Deutsche Bank y Commerzbank. Santander cuenta con 1,5 billones de euros y BBVA, con 715.000 millones. A nivel mundial, excluidos los gigantes chinos, los mayores bancos por volumen de activos son JP Morgan Chase y Bank of America.

Deutsche, aunque ha entrado en beneficios, es un barco a la deriva; sus problemas se mantienen, a los que se añaden los de reputación por los diversos escándalos por manipular el libor. Además, mantiene una exposición a derivados cuatro veces superior a todo el PIB de la Unión Europea.

Tras fracasar la fusión, surgía que el mayor banco italiano, Unicredit, mostraba su interés por Commerzbank, con el propósito de fusionarlo con su filial HypoVereinsbank (sexta entidad alemana). Paralelamente, se mantenían conversaciones entre las divisiones de gestión de activos de Deutsche Bank y de UBS, lo cual parecía tener un mayor sentido. Pero ninguna de estas operaciones ha prosperado. Pero sí lo hicieron en EE UU. Por primera vez desde la crisis financiera de 2008, los bancos estadounidenses BB\&T y SunTrust anunciaron su fusión, valorada en 66.000 millones $\triangleright$

9 Wirecard, entidad bancaria alemana que opera solo por internet, cuenta con una capitalización en torno a 18.700 millones de euros. 
de dólares, creando la sexta mayor entidad financiera del país por activos (442.000 millones de dólares), préstamos (301.000) y depósitos (324.000).

\section{La evolución del mercado bancario europeo y los nuevos competidores digitales}

La evolución del mercado bancario europeo gravita sobre tipos de interés negativos, que presumiblemente van a perdurar en el futuro. La zona euro se encuentra aún muy distante de la normalización monetaria. La inflación es baja y está lejos del objetivo cercano al $2 \%$, mientras que la desaceleración de la economía está siendo más prolongada de lo que se esperaba. El consumo se mantiene firme, pero la inversión pierde ímpetu y el sector exterior acusa la debilidad del comercio internacional. Las condiciones de financiación son atractivas y la política fiscal tiende a relajarse. En tanto, la Reserva Federal de Estados Unidos giró el rumbo de su política monetaria y, por primera vez en más de una década, recortó los tipos de interés, situándolos en el rango del $2 \%$ y el 2,25\%, en un intento por sostener el crecimiento económico del país frente a la desaceleración global y las turbulencias causadas por las disputas comerciales con China.

En este contexto, los bancos deben de propiciar mayores flujos de ingresos. Una posibilidad se encuentra en aumentar las tasas, las comisiones y otros servicios comerciales como palancas para aumentar la rentabilidad durante los próximos años, donde se encontrarán con nuevos competidores, las llamadas FinTech y las BigTech.

Las BigTech, que pretenden ser el Uber financiero, se diferencian de las FinTech, principalmente, en que las primeras cuentan con un enorme capital, la tecnología más avanzada y una presencia global. Las segundas representan una industria que aplica tecnologías avanzadas a actividades financieras y de inversión mediante nuevas aplicaciones, procesos, productos y servicios financieros complementarios únicamente por internet, mediante herramientas tecnológicas sencillas, con costos más competitivos que los de los bancos.

Constituyen las BigTech las compañias tecnológicas más grandes del mundo, conocidas por el acrónimo GAFA (Google, Amazon, Facebook y Apple). A este grupo se le añaden otras grandes como Microsoft, Samsung y Paypal, más las asiáticas Baidu, Alibaba y Tencent, conocidas como BAT. Fundamentan su modelo de negocio en menores costes, ya que ofrecen servicios gratuitos. Su objetivo no es conseguir mayores ingresos, sino mejorar la cadena de valor y monetizar la información del cliente mediante la venta de productos y publicidad. Este modelo de negocio tiene un conflicto básico entre ingresos y privacidad del usuario, lo que quiere decir que cuanto menos privacidad, más ingresos por publicidad se obtienen. En ese ámbito, los bancos cuentan con una ventaja competitiva: el uso responsable de los datos y la confianza de los clientes. Su negocio no es vender datos, ni generar ingresos por publicidad. Su factor diferencial representa históricamente la piedra angular de su negocio: la confianza.

Aunque las BigTech se proclaman modernizadoras de la forma en que los consumidores gestionan su dinero y las empresas realizan el comercio y sus operaciones. Afirman que sus servicios financieros son más accesibles, asequibles y seguros para todos y, en consecuencia, promueven políticas que permitan estas innovaciones. Argumentan que $D$ 
tienen la capacidad de mejorar, en gran medida, la forma en que las familias y las pequeñas empresas ahorran, piden préstamos, realizan transacciones e invierten; por ello resultan tan peligrosos para el negocio de la banca comercial, ya que golpea al corazón de su negocio.

La noticia de que Google se ha asociado con Citigroup y con una cooperativa de crédito local de California para ofrecer cuentas corrientes a partir de 2020 está corriendo como la pólvora en los despachos de los banqueros españoles. Citigroup gestionará la mayoría de los requisitos financieros y de cumplimiento regulatorio. Los clientes accederán a sus cuentas a través de la aplicación Google Pay. Apple se asoció este año con Goldman Sachs Group para ofrecer una tarjeta de crédito. JP Morgan Chase está diseñando una billetera electrónica que daría cobertura a compañías como Airbnb o Amazon, con la capacidad de proporcionar a los clientes cuentas bancarias virtuales.

Facebook ha dado un paso audaz con su proyecto «libra» ${ }^{10}$, la creación de una nueva criptomoneda (18 de junio de 2019.) Dicho proyecto se encuentra aún en la fase de definición, contando, por el momento, con manifestaciones de interés por parte de veintiocho socios estratégicos de procedencias diversas: compañías de tecnología, algunos actores relevantes de la industria financiera, representantes de organizaciones sin ánimo de lucro y profesionales del entorno académico, entre otros. Según sus promotores, la libra nace con el propósito fundamental de contribuir a mejorar los actuales niveles de inclusión financiera mundiales. En concreto, busca combinar las características de una moneda virtual, de alcance global y

10 Banco de España (otoño, 2019): Informe de Estabilidad Financiera. «Recuadro 3.2. El proyecto Libra: características y riesgos destacados». baja volatilidad, con las de una infraestructura que permita realizar transacciones de una manera ágil y eficiente. Para ello, se basa en la tecnología de blockchain, los monederos digitales y los contratos inteligentes.

En comparación con otras criptomonedas ${ }^{11}$, la libra presenta una serie de diferencias notables. Por un lado, prevé estar respaldada por una cesta de depósitos y otros activos de bajo riesgo y elevada liquidez. Dicha cesta, conocida como Reserva Libra, estará denominada en las principales divisas del mundo y será administrada por una red de custodios a nivel mundial. Los rendimientos que generen dichas inversiones servirán para cubrir el coste del sistema y remunerar a los socios. Lógicamente, las variaciones que se produzcan en los precios de los activos subyacentes influirán en el precio que en cada momento tengan las unidades de libra en cualquier divisa nacional. La libra, al ser una moneda global, a cuya información tendrán acceso más de 2.400 millones de potenciales usuarios con apenas costes de transacción, puede contribuir significativamente a la transmisión internacional de perturbaciones locales al favorecer las entradas y salidas de capitales, con implicaciones relevantes para la evolución y la volatilidad de los tipos de cambio.

A la banca le preocupan estas iniciativas, pero le preocupan más proyectos como los de Alipay $^{12}$ (Alibaba) y Wechat en China, que $\triangleright$

\footnotetext{
11 Libra es una criptomoneda de emisión privada. Para un análisis detallado de las ventajas e inconvenientes de la emisión de moneda digital por un banco central, véase: Central Bank Digital Currencies, BIS, Committee on Payments and Market Infrastructures and Markets Committee (marzo, 2018).

12 Alipay, que pertenece al grupo de Ali Baba, es una plataforma móvil de terceros y pago en línea. En 2015, igualó a la plataforma más grande del mundo de pago móvil, PayPal. En 2018, el número de usuarios en Alipay alcanzó los 870 millones. Actualmente, es el líder de servicio de pago móvil del mundo y el segundo servicio de organización de pagos móviles. En España, El Corte Inglés incorporó Alipay en todos sus sistemas y terminales de pago para ofrecer a los clientes de origen chino un servicio más personalizado.
} 
ofrecen al comercio y a los clientes pagos digitales sin necesidad de contar con bancos. No obstante, las BigTech no parecen muy interesadas en convertirse en bancos, ni en captar depósitos, lo cual las obligaría a someterse a una regulación muy exigente. De manera que en unas áreas específicas representan una amenaza, pero en otras pueden convertirse en un aliado potencial o en un proveedor de servicios en ámbitos concretos geográficos.

El Informe de Estabilidad Financiera del Banco de España (otoño, 2019) recoge explícitamente como un riesgo «los cambios tecnológicos y, más en concreto, las criptomonedas». En este sentido, detalla que «la creación de monedas virtuales puede afectar significativamente a la efectividad de la política monetaria, así como a la estabilidad financiera por la prociclicidad de la oferta de dinero agregada, el impacto en las entidades financieras o en los mercados de divisas, así como ciertas vulnerabilidades adicionales sobre países con cierta inestabilidad financiera».

Las BigTech podrían controlar en el futuro cercano casi 9 billones de euros, que actualmente manejan los bancos comerciales españoles. Su llegada significa un reto desconocido y peligroso. Todo un desafío para el conjunto del sector financiero. Las BigTech están centrándose en tres grandes servicios: transferencias bancarias, pagos con tarjeta y créditos al consumo. $\mathrm{Y}$ pronto ampliarán su oferta a todo tipo de productos, como las hipotecas o los préstamos personales. Tampoco se encuentran fuera de su alcance los «fondos de inversión", pues ya se pueden adquirir por internet.

Más aún, con el impulso a la banca abierta tras la transposición definitiva de la Directiva PSD2 de Servicios de Pago (Payment Services
Directive 2) ${ }^{13}$, cuyo objetivo es aumentar la seguridad y la confianza de los usuarios en este tipo de gestiones que la UE elaboró y aprobó en 2015 , la cual ya es posible desde septiembre de 2019. Desde este momento se abrirá una mayor competencia al obligar a los bancos a facilitar los datos de sus clientes a todos los competidores. Las consecuencias no se han hecho esperar y las GAFA han comenzado la compra de licencias bancarias en la Unión Europea: Google en Lituania, Amazon en Luxemburgo y Facebook en Irlanda.

El Banco de España, en 2018, fijó el crédito de la banca española en 88.670 millones de euros (consumo e hipotecas) y la de los establecimientos financieros de crédito en 34.799 millones de euros ${ }^{14}$ (consumo y automoción). En cuanto al número de transferencias, el Banco de España e Iberpay (Sociedad Española de Medios de Pago) estiman que se realizaron más de 1.500 millones por un valor de 8,5 billones de euros. Sobre el pago con tarjetas (crédito y débito) el Banco de España recoge 3.903 millones de operaciones valoradas en 147.431 millones de euros. Además, los fondos monetarios contaban con un patrimonio de 6.800 millones de euros.

La suma de todos estos servicios asciende a casi 9 billones de euros. Por lo cual, un sector más abierto traerá una nueva dinámica con más oportunidades para las BigTech, que venderán sus servicios como un claro $D$

\footnotetext{
13 La directiva PSD2 ha hecho que adquiera una gran importancia el modelo de banca abierta, que conlleva una nueva dimensión que se traduce en poder colaborar con terceros para crear mejores soluciones digitales y ayudar a otras empresas en su transformación digital. La banca abierta es un nuevo modelo bancario comparable al nacimiento de la banca telefónica u online. Para ello, las entidades deben activar un sistema tecnológico mediante API abiertas (enlaces tecnológicos que contienen información). De esta forma, terceras empresas pueden acceder a sus datos y obtener información sobre el comportamiento financiero de sus usuarios. Euro Banking Association (EBA) cuenta con vídeos muy útiles en los que se explica con claridad en qué consiste la banca abierta.

14 Asociación Nacional de Establecimientos de Crédito.
} 
componente de beneficio para los clientes. Dicho lo cual, la banca española ha reaccionado tecnológicamente en tiempo y forma de manera muy eficiente, hasta convertirse en líder sectorial europeo y mundial. Los múltiples premios recibidos a nivel mundial así lo acreditan.

Las BigTech, encabezadas por las GAFA, con el «argumento» de favorecer el espíritu emprendedor y la innovación, presionan a favor de una regulación menor, más laxa y de tratamientos fiscales ventajosos, lo que han conseguido de los respectivos Gobiernos hasta la fecha. Santander, en el plano fiscal, encabeza un movimiento empresarial cuyo objetivo es que se dicten las leyes correspondientes para que las BigTech cumplan como lo hacen los demás bancos: «Tanto vendes, tanto pagas».

A su vez, las GAFA se están convirtiendo en monopolios que establecen su propio marco de gobernanza. ¿Qué cree que hay que hacer? $¿$ Cree que hay que romper monopolios como los del Google, Facebook o Amazon?, le preguntaban a la presidenta del Grupo Santander, Ana Botín, quien responde: «Vivimos en otra plena revolución industrial: la revolución digital. Para competir y alcanzar justicia social, necesitamos una regulación que fomente una competencia efectiva, incluyendo un marco fiscal equitativo. Para ello, necesitamos nuevas normas adaptadas a la era digital. A día de hoy, esto nos es así. En particular, necesitamos asegurar que todas las empresas que ofrecen los mismos servicios se regulen de la misma manera. Necesitamos un marco regulatorio que contemple el poder y el valor de los datos: las empresas deben compartir los datos de manera justa, protegiendo la privacidad de los ciudadanos y asegurando que se compite en igualdad de condiciones. Los reguladores deben actuar ahora para abordar todos estos puntos; no regular a través del espejo retrovisor que nos muestra el mundo analógico que hemos dejado atrás, sino hacerlo para la era digital que está ya aquí; y hacerlo cuanto antes» ${ }^{15}$.

A su vez, la economista jefe de la OCDE, Laurence Boone, considera que, «a nivel mundial, tenemos que cerciorarnos de que las empresas paguen lo que les corresponde en impuestos, para generar valor y empleo para la gente» 16 .

\section{La evolución de la banca y el BigTech Banking}

El Observatorio de la Digitalización Financiera de Funcas y KPMG, en su informe La banca ante las BigTech (28 de noviembre de 2019), considera que el futuro de los bancos pasa por firmar alianzas con los socios adecuados para poder seguir compitiendo con éxito en los servicios financieros. Si lo anterior se cumple, representaría la confirmación de que los bancos se encuentran en una «evolución» que va mucho más allá que las tendencias generalizadas y se perfila como una auténtica reinvención llamada BigTech Banking; la respuesta efectiva a la amenaza encabezada por las GAFA.

El informe muestra que todas estas grandes compañías digitales ya compiten directamente con los bancos comerciales. Los créditos al consumo, los pagos (incluyendo el cambio de divisas) y los seguros son las áreas de negocio donde tienen mayor actividad. No es casualidad que sean las áreas con un $\triangleright$ 2019

15 Entrevista a Ana Botín, La Vanguardia, Barcelona, 26 de mayo de desigualdad de ingresos es importante: Cómo garantizar que La crecimiento económico beneficie a muchos y no a pocos. Participaron en el seminario: la directora gerente del FMI, Christine Lagarde, y las economistas jefes del FMI, Banco Mundial y OCDE, Pinelopi Koujianou Goldberg, Gita Gopinath y Laurence Boone. 
mayor volumen de mercado y mejores márgenes de beneficio. Sin embargo, de momento, el negocio relacionado con los depósitos sigue siendo un terreno que no les resulta atractivo, tanto por la regulación que se le aplica como por la actual situación de los tipos de interés.

Hasta ahora los bancos veían cómo la estricta regulación a la que está sometido el sector financiero les protegía de la competencia de estas grandes compañías digitales. Pero las BigTech han encontrado fórmulas para desarrollar sus propios servicios financieros sin ser reguladas como un banco. El Consejo de Estabilidad Financiera (FSB), uno de los principales organismos responsables del funcionamiento de los sistemas financieros del mundo, ha publicado un informe en el que insta a las autoridades globales a permanecer alerta frente a los posibles impactos del auge de los servicios financieros de las GAFA sobre la estabilidad financiera.

Las BigTech han logrado obtener licencias para operar como entidades de pago en Europa, Estados Unidos, México o India. Estas licencias permiten desarrollar servicios de envío de dinero, abrir cuentas para ingresar y recibir dinero en efectivo, gestionar transferencias, abrir líneas de crédito de menos de doce meses, realizar ejecuciones de órdenes de pago telemáticas y desplegar servicios de medios de pago entre países. A continuación, buscan establecer alianzas con entidades financieras que les permiten entrar en negocios más regulados y supervisados. Este debe contar con una gran experiencia respecto al cumplimiento normativo en las distintas geografías. Mientras tanto, continúan centrándose en ofrecer productos innovadores y los mejores servicios al menor coste. Así es el modelo de la tarjeta Apple, emitida por Goldman Sachs, pero concebida y diseñada por Apple. De hecho, los problemas con su algoritmo, que ofrecía un crédito más limitado a las mujeres, abrieron un debate sobre los previsiblemente múltiples dilemas que van a llevar implícitas estas nuevas alianzas. Por su parte, Amazon tiene como socio a Bank of America para ofrecer el servicio de préstamos en EE UU, Reino Unido y Japón. Esta alianza le permite realizar operaciones entre 1.000 y 750.000 dólares. En los siete años de funcionamiento, Amazon ha otorgado préstamos a 20.000 pymes por valor de 3.000 millones de dólares. Como Apple y Amazon, la mayoría de las compañías digitales trabaja con alguna entidad financiera. El $26 \%$ de las entidades ya se está asociando con una o más compañías tecnológicas, y un $27 \%$ adicional asegura que está a punto de cerrar una alianza en el futuro.

Efectivamente, los anuncios de nuevas alianzas se suceden uno tras otro: Google anuncia el acuerdo con Citigroup para en 2020 permitir gestionar cuentas bancarias desde Google Pay; y Facebook anuncia su criptomoneda libra, con la colaboración de Visa, Mastercard y Paypal. Esto es solo la punta del iceberg del cambio que se avecina. "Solo las entidades que resulten útiles a sus clientes son las que van a ser capaces de competir en el futuro, siendo fundamental elegir el socio adecuado para asegurarse el éxito e incluso la supervivencia» (Francisco Uría, KPMG).

La buena noticia para el sector financiero es que la gran mayoría de los bancos lleva años preparándose para este cambio y dedicando elevadas inversiones y esfuerzos en su transformación digital. BBVA es un claro ejemplo: su transformación conlleva la firma de múltiples alianzas con FinTech, proveedores tecnológicos y grandes plataformas. El mejor ejemplo es el caso de Uber en México, donde BBVA Bancomer, directamente desde la app de Uber, ofrece una cuenta corriente y servicios de financiación a todos los conductores de la $\triangleright$ 
plataforma. Una colaboración muy en la línea del modelo que está marcando el BigTech Banking. Aun así, el reto que afronta el sector financiero es enorme, pues las BigTech tienen importantes ventajas a su favor. Son compañías globales con un gran dominio tecnológico y unas infraestructuras mucho más preparadas para competir en el mercado digital. Tienen además grandes economías de escala, pero lo principal es que son capaces de crear servicios muy prácticos y fáciles de usar. En definitiva, desarrollan experiencias de usuario únicas y diferentes, que atrapan a sus clientes y que marcan el nivel de exigencia para todo el que quiera competir en servicios financieros digitales.

De ahí que cada vez haya más usuarios de banca predispuestos a considerar alternativas de productos en entidades no financieras. Según el informe, 4 de cada 10 clientes contrataría servicios financieros en Google, Amazon o Apple. El $47 \%$ estaría dispuesto a abrir una cuenta con una de estas compañías, siendo la opción más deseada Google (15\%), seguida de Amazon y Apple ( $13 \%$ y $11 \%$ ), y Facebook es la menos escogida. Sin dudas, la crisis de Cambridge Analytica tiene mucho que ver con esta falta de confianza.

Precisamente este punto, el de la protección de los datos y la confianza, pone en evidencia dónde puede estar la gran baza de la banca en este cambio de paradigma. Las grandes fortalezas del sector financiero se encuentran en la seguridad, la privacidad y el cumplimiento legislativo, «cada vez más importantes y difíciles de replicar por parte de las BigTech. La clave, está precisamente en buscar los socios adecuados y crear una relación que beneficie a ambas partes. «Si bien estos cambios necesitarán su tiempo, desarrollar acuerdos sólidos de colaboración con los gigantes tecnológicos es un paso positivo en la dirección adecuada que abrirá oportunidades para un mayor crecimiento y cambio en el futuro", concluye el informe.

\section{Los bancos y la evolución de la rentabilidad}

La banca española, y por extensión la europea, se encuentra en una situación no solo desconocida para su negocio al operar con tipos de interés negativos, que presionan sobre los ingresos y, en consecuencia, afecta a su rentabilidad.

Esta recomendación ha sido planteada en varias ocasiones por el Banco de España y por la Autoridad Bancaria Europea (EBA). Concluidos los resultados del ejercicio de transparencia y después de recopilar los datos de los bancos de la UE, una de las principales conclusiones fue que la rentabilidad de los bancos europeos continúa siendo baja. Lo cual es evidente que le preocupa, dada la actual desaceleración de la economía. «La rentabilidad es una preocupación para nosotros. Los bancos han mejorado sus ratios de capital en los últimos años y han disminuido el volumen de préstamos morosos. Eso es realmente bueno, significa que los balances se han fortalecido. Pero, al mismo tiempo, la rentabilidad continúa siendo baja durante varios años. Está por debajo de los costes estimados de capital. Esto representa un desafío, porque el entorno macroeconómico es exigente. Los bancos necesitan encontrar la manera de mejorar la rentabilidad» (José Manuel Campa, presidente de la EBA $)^{17}$.

Tiempos convulsos, vibrantes y peligrosos para el sector bancario, que le exige afinar sus pasos, sus movimientos, su estrategia. Es un hecho que el mercado se encuentra sufriendo $D$

17 El Economista (5 de diciembre de 2019). 
tal alteración histórica, que nos hace cuestionarnos, incluso, el propio concepto de lo que es la banca, cuyo origen resulta muy difícil de fijar para los historiadores, pues el fenómeno bancario, en cierto modo, lo encontramos desde la más lejana antigüedad.

La crisis y su legado están golpeando a la banca como nunca y la ha afectado como institución, agravada por las alteraciones que se experimentan en el entorno sociopolítico que se extiende por España, Europa, América Latina, EE UU y el mundo. Sin duda, todas esas alteraciones que se conectan, interconectan y retroalimentan explican los profundos cambios en el mundo específico de la banca y en la actividad financiera en general.

Por supuesto que en todo cambio hay alteraciones y que en ocasiones no son más que la aplicación de tendencias generalizadas. Pero hoy es diferente, las exigencias económicas y financieras ya no son los que eran. Si bien la banca, como toda empresa, se moderniza estructuralmente, esto es, en todas sus áreas, campos y ámbitos de actuación, y asume la innovación como un reto permanente que afecta e impacta en toda la organización. En este contexto, asume su rol económico y acepta su responsabilidad social, pero, aun así, nos hace ver que estamos ante algo más radical y profundo del negocio.

La realidad trasmite una sensación de cambio sin tregua ni descanso, como nunca antes se había producido. Asistimos hoy, en efecto, al fenómeno de un sector que, regulado con minuciosidad, siente drásticamente el peligro de que su operativa más típica, como es el negocio de la banca comercial, se le escape. Comprueba cómo penetran otros competidores no financieros, regulados de manera más débil y menos minuciosa y de rasgos conceptuales bastantes diferentes. Ayer eran los grandes almacenes y las entidades emisoras de tarjetas de crédito, y hoy son las FinTech y BigTech.

Además, comprueba cómo sus clientes, por un lado, buscan modalidades de financiación alejadas del crédito bancario tradicional y, por otra parte, se sienten estimulados para situar sus ahorros fuera del sistema bancario. De manera que los bancos ven invadidos sus tradicionales posiciones y mercados. Pero, a su vez, ellos invaden otros en los que nunca habían pensado, al tiempo que las interconexiones bancarias se refuerzan para incluir a empresas no financieras y tecnológicas de un amplio espectro, creando lo que se conoce como grupo o conglomerado tecnofinanciero.

El cambio es tan rápido, tan frenético, tan multidimensional, que es importante y urgente preguntarse por su sentido más profundo. ¿Qué está cambiando? ¿Por qué? Desde luego, está cambiando el propio contenido bancario, incrementando su grado de sofisticación tecnológica a la vez que se difuminan los propios límites de la actividad y de la «profesión». Los porqués de este proceso de mutación son varios, y no es fácil discernirlos, ni separarlos con precisión ni atribuir el efecto que se corresponde a cada uno de ellos.

En todo caso, esta situación no es en absoluto una novedad para la banca. Aunque muy probablemente se haya así reconocido. Al contrario, es algo consustancial con su devenir, con su propia existencia. Todo esto ya lo advertía y lo expresaba con toda lucidez el banquero más intelectual de la banca española, el catedrático de Hacienda Pública y Derecho Fiscal, presidente del Banco de Bilbao y posteriormente del Banco Bilbao Vizcaya, José Ángel Sánchez Asiaín (marqués de Asiaín desde 2010): «La mutación es de tal intensidad que todos los sistemas bancarios se cuestionan hoy cuál va a ser en el futuro su actividad $\triangleright$ 
genuina y su producción. Lo que no sucede en otros sectores productivos, en los que el cambio puede llevar a cuestionar cuánto se debe de seguir produciendo, lo que siempre han hecho. Por ello, la banca se plantea en estos momentos un problema profundo e inédito en su historia: la crisis de su propia existencia y la de su función, es decir, una crisis de identidad (con lo peligroso que esto resulta) que obliga a buscar nuevos espacios (formas y maneras) para el negocio bancario. Crisis, por otra parte, con complejas raíces exteriores, porque lo que constituye el entorno de la banca, la sociedad, la economía, están sometidas, a su vez, a órdenes nuevos, cuya novedad consiste, precisamente, en que el cambio, rápido y radical, es su rasgo más permanente» 18 .

\section{Conclusiones ni definitivas ni cerradas}

La banca tradicional es un negocio maduro, el cual no es solo dinero. El banquero debe empezar a pensar que el negocio ya no es solo dinero, que, ciertamente, se mueve cada vez más a mayor velocidad, a mayor distancia, y es recogido y asignado en grandes volúmenes y con márgenes más estrechos; sino que ahora existe otra materia prima básica, implícita en la esencia misma del dinero, pero que lo supera y lo convierte a un estadio superior: la información. La información añade valor al servicio que se le brinda a la clientela, con capacidad de ser facturada y proporcionar crecientes ingresos.

Así las cosas, el negocio bancario se está convirtiendo, cada vez más, en un trasiego de

18 José Ángel Sánchez Asiaín (26 de mayo de 1987): Reflexiones sobre la banca. Los nuevos espacios del negocio bancario. Discurso de recepción del académico de número Excmo. Sr. D. José Ángel Sánchez Asiaín y contestación del Excmo. Sr. D. Enrique Fuentes Quintana. Real Academia de Ciencias Morales y Políticas. Madrid. datos e informaciones y menos en un cauce de circulación de dinero. Este es cada vez más un producto informativo, como consecuencia de las nuevas tecnologías, que han alterado incluso la noción de soberanía. No obstante, llegará un momento en que la información será fácilmente accesible, estará suficientemente divulgada y la cultura financiera alcanzará un buen nivel. Y si, además, las estructuras y los sistemas de información se descentralizan y se extienden en redes de comunicaciones generales y se puede operar con una autonomía compatible, con un control y garantías comunes, la banca cambiará muy profundamente, pues habrá cumplido fielmente con su función. Posiblemente en ese momento, la banca, como la entendemos ahora, ya no existirá. El poder de la tecnología habrá alterado su negocio. De modo que, cuando se pueda superar este estadio, probablemente será sustituida igual que el papel moneda sustituyó a la moneda metálica ${ }^{19}$.

Definitivamente, la banca española y mundial se encuentra sumida en una "evolución», que le hace reflexionar sobre su propio negocio, desde los condicionantes que la aprisionan para seguir ejerciéndolo como lo ha hecho durante siglos: la intermediación financiera entre ahorradores e inversores. Ahora el negocio se encuentra muy presionado por el efecto de la prolongada laxitud de la política monetaria y los tipos de interés negativos, y esto hace pensar a la banca en cómo establecer nuevas fórmulas de negocio que pasan necesariamente por el ámbito tecnológico, lo cual también incide sobremanera en su planteamiento tradicional del negocio en busca de aumentar los ingresos y, en consecuencia, la rentabilidad.

19 La banca española. Análisis y evolución (Prólogo de José María Amusátegui), (Casilda, 1997). 
Con un euribor en negativo y sin horizontes inmediatos de subida es difícil hacer crecer los márgenes de intermediación. Los bancos llevan años saneando sus balances y durante un tiempo se beneficiaron de una política monetaria expansiva, que permitió que no se colapsara el sistema. Pero la excepción monetaria se ha convertido en la regla y todo apunta a que la era de tipos negativos se prolongará durante un tiempo más largo de lo esperado ${ }^{20}$. Esto condiciona más a los bancos que tienen la mayor parte de su negocio en España, debido a que su capacidad para compensar su rentabilidad es limitada. $Y$ no solo por las restricciones que impone la regulación bancaria, sino por la intensa competencia del sector y sus nuevos jugadores. A lo que el Banco de España ha recomendando contención y prudencia al otorgar crédito hipotecario y al consumo. Lo paradójico es que estas son una de las palancas que puede mejorar las cifras de negocio.

$Y$ tampoco se hace fácil obtener mayores ingresos por la gestión de recursos fuera de balance, y del ahorro de costes no se puede vivir eternamente.

¿Qué podría hacerse? Los costes operativos de la banca son un primer aspecto importante. En primer lugar, la ratio costes-ingresos se ha mantenido estable durante los últimos años. Aunque han aumentado ligeramente en el último año. En segundo lugar, tal como ya lo están haciendo, los bancos deben invertir en la digitalización y la transformación de sus modelos de negocio. En tercer lugar, los bancos realmente tienen que intentar ser más efectivos al decidir sobre su rentabilidad, que ha perdido entre un $30 \%$ y un $50 \%$ de su valor en bolsa. En cuarto lugar, más de un experto

20 Una anormalidad que, si bien puede facilitar el crecimiento de la endeble economía de la eurozona, también hace que surjan dudas sobre su efectividad, pues puede tener efectos colaterales perniciosos. indica que cobrar por los depósitos sería la solución, siempre y cuando la clientela lo acepte. En quinto lugar, la alternativa de que elija operar con las diferentes FinTech, que proliferan cada día, pero cuidado: las GAFA, con su portentoso poder de mercado, imponen cautela. $Y$ finalmente, en sexto lugar, la consolidación puede ser la respuesta más efectiva del sector.

$Y$ recuerden: ¿Qué es el mercado? Es la ley de la selva ¿Qué es la selva? Es la ley de la naturaleza. ¿Qué es la naturaleza? Es la ley de la civilización. ¿Qué es la civilización? Es la lucha contra la naturaleza ${ }^{21}$.

\section{Bibliografía}

Álvarez, J. A. (2008). La banca española ante la actual crisis financiera. Revista de Estabilidad Financiera (15). Banco de España. Madrid. Recuperado de https://www.bde.es/

Arderiu, A. (20 de enero de 2016). Fusiones bancarias y economías de escala. Cinco Días. Madrid.

Bolsa y Mercados de España (2015). Posición Internacional de la Empresa Cotizada Española. Madrid.

Casilda Béjar, R. (1997). La banca española. Análisis y evolución. Madrid: Editorial Pirámide.

Casilda Béjar, R. (2019). Capitalismo. Crisis y reinvención. Valencia: Tirant.

Muñoz, R. (2016). Las lecciones no aprendidas del sistema financiero español. Dos crisis en perspectiva en el marco normativo de la Unión Europea. Revista Via luris (20). Facultad de Jurisprudencia y Ciencias Políticas y Sociales de la Universidad de Cuenca. Cuenca.

21 En un debate sobre qué es el mercado entre Alan Greenspan y su correligionario liberal al que no reconocía como tal, Edouard Balladur, este le respondió con un soliloquio. 